\title{
Dating Capital Market Integration In The EMU
}

Sergiy Rakhmayil, Ryerson University, Canada

\begin{abstract}
This paper analyzes the effect of the Euro on structural breaks in financial market variables in a sample of three EMU (France, Germany, Netherlands) and two non-EMU (U.K. and Switzerland) countries from March 1984 to November 2002. We identify two dates when integration-related structural breaks occurred in European asset pricing; the first in 1986 affected all sample countries whereas the second in 2000 affected only the EMU countries and could be attributed to the adoption of Euro in 1999.
\end{abstract}

Keywords: International Asset Pricing; Currency Risk; Liberalization; European Union; Time-varying market integration

\section{INTRODUCTION}

¿ mplementation of the Euro by the European Monetary Union (EMU) has produced a profound effect on all aspects of financial transactions throughout Europe. The common currency is just one of many steps towards financial liberalization in participating countries. The liberalization process involved several European countries and spanned over several decades starting in January 1979 which makes it difficult for researchers to model the integration process. Several prior studies have examined this issue using different methodologies and country samples with mixed evidence. Our study adds to this literature by estimating the dates of structural breaks in European equity pricing.

We use a sample of three EMU (France, Germany, Netherlands) and two non-EMU (U.K. and Switzerland) countries using monthly data from March 1984 to November 2002. Our main focus is to examine the impact of the European liberalization process on stability of both market pricing for the European capital markets. Specifically, we investigate whether equity pricing had structural breaks, estimated the dates of the breaks, and provide confidence intervals using the methodology in Bekaert et al. (2002).

We perform a number of univariate and multivariate tests to check robustness of these breaks using financial and macroeconomic variables suggested in Bekaert et al (2002). We also examine whether the estimated structural dates are related to any political events in the European markets such as the implementation of the Single European Act, the Maastricht Treaty, and the introduction of the Euro.

Our main findings are as follows. We document that structural changes in equity pricing occurred around June 1986 for all countries in our sample. However, the countries that implemented the Euro also experienced a second series of breakpoint dates that occurred at different times around January 1999. These results are consistent with prior research on financial integration, including Errunza and Losq (1985), Bekaert, and Harvey (1995), and Bekaert et al (2002), among others, that the economic liberalization process leads to a higher integration of the country markets in the region.

Our study makes contribution to the literature by estimating structural breaks dates. To the best of our knowledge, this is the first paper that estimates dates of structural breaks in European asset pricing related to market integration. This paper is organized as follows. The next section outlines the estimation method, and section 3 describes the data set. Section 4 presents our finding for the asset pricing processes within Europe and provides estimates of the dates where integration-related structural changes most likely occurred. Section 5 concludes. 


\section{METHOD FOR DATING THE INTEGRATION PROCESS}

We estimate the integration-related structural changes in asset pricing of all countries in the sample by using Bekaert et al (2002) methodology. They suggest a test for market integration based on the supremum of Wald test statistic or Sup-W test introduced by Bai et al (1998). This test performs a Wald test for structural change in $q$ parameters of the vector autoregression of order $p$ for each data point,

$$
y_{t}=A_{1} y_{t-1}+\ldots+A_{p} y_{t-p}+C+\lambda_{t}
$$

In equation (1) $y_{t}$ is a $n \times 1$ vector of variables, $A_{j}, j=1, \ldots, p$ is a $n \times n$ matrix of coefficients, $C$ is a $n \times 1$ vector of constants, $\lambda_{t}$ is a $n \times 1$ vector of residuals, and the number of parameters $q=n(n p+1)$.

We use the Akaike information criterion to determine lag length $p$. The structural changes could occur due to market integration, or due to other events relevant to the stock markets, and there is no way to tell whether it is specifically integration-related structural breaks or not. To achieve higher degree of certainty, one might want to compare the estimated dates of the breaks with changes in the estimated measures of integration for each country, and with the timeline of the political events. We do the latter comparison in this study, and leave for future research the more detailed comparison of trajectories for the estimated measures of integration with the estimated breakpoint dates. Another option would be to test for structural breaks in our fully or partially integrated models. However, this approach has two shortcomings. First, there is no way it can pinpoint a precise date, or even a confidence interval of actual structural change, since the Chow-type test statistic is a function of the pre- and post-date subsamples. Second, our models, especially the model assuming time varying integration, have a very large number of parameters compared with the number of data points in the sample, which poses a serious problem with degrees of freedom.

The estimated date of structural change $k$ will maximize the Sup-W test statistic $F_{T}(k)$. In order to compute confidence intervals for the estimated date of structural change, we use critical values for the test statistics provided by Bekaert et al (2002). We estimate several univariate and multivariate autoregressive specifications for each country. Our base case for an individual country VAR includes 4 variables: country index return, country dividend yield, European index return, and European dividend yield.

\section{DATA AND DESCRIPTIVE STATISTICS}

We analyze the influence of the European monetary unification on stock market integration in a sample of five countries that include three EMU (France, Germany, the Netherlands) and two non-EMU (U.K. and Switzerland) countries. France and Germay are the largest EMU economies whereas the Netherland is one of the smaller EMU members. The U.K. has been used in several prior studies to examine the effect of the European liberalization on the non-EMU countries (See for example De Santis and Gerard, 1998, Carrieri, 2001, Fratzscher, 2002, De Santis et al, 2003, Hardouvelis et al, 2005). The Netherlands has one of the highest investment rates in Europe and invests over 30\% of its institutional investments abroad (See Statistics Netherlands dossier on population ageing and Solnik and McLeavy, 2002) ${ }^{1}$. We also include Switzerland because it has a large and international banking system as well as several large multinational corporations. Further, unlike the U.K., Switzerland was never a part of the EMU process and may provide better estimates of time -varying market integration for non-EMU countries.

We use five country indices, and the European market index. The monthly returns from March 1984 to November 2002 for the five European stock market indices and for the European market index are obtained from Morgan Stanley Capital International ${ }^{2}$. We measure the riskless rate as the one-month Eurodollar rate and riskless

\footnotetext{
${ }_{2}^{1}$ See http://www.cbs.nl/en-GB/menu/themas/dossiers/vergrijzing/publicaties/artikelen/2004-1574-wm.htm

2 www.msci.com
} 
rates for European countries are obtained from the dataset that accompanies the Solnik and McLeavey (2002) textbook on international investments. ${ }^{3}$ The data on the Eurodollar rate and the US government bond yields are obtained from the US Federal Reserve Board website ${ }^{4}$.

Table 1 presents the descriptive statistics for the stock market excess returns. The stock returns for all the five countries and the European index exhibit significant differences across countries. The U.K. has the lowest mean of $0.1442 \%$ per month (or roughly $1.7 \%$ per year) whereas Switzerland displays the highest mean excess return of $0.5202 \%$ per month (or roughly $6.4 \%$ annualized return) The standard deviation of returns, on the other hand, is the highest in Germany (0.07802) and the lowest in the U.K. (0.064653), except for the European stock market index.. All stock series are stationary based on the ADF test, although the hypothesis of normality is rejected by the JarqueBera statistic.

Several previous studies, for example Dumas and Solnik (1995), De Santis and Gerard (1998), or Carrieri (2001) use a set of instrumental variables that convey information about the market and economic conditions in the European marketplace, as well as in each country. In all of the studies the most important factor in stock pricing is lagged dividend yield. Thus, we use the lagged dividend yield as stock pricing information variable relevant to structural change in stock pricing. Descriptive statistics for the European and country-specific dividend yields (XDY) in excess of the corresponding riskless rate are presented in Table 1.

Table 1. Excess returns and dividend yields

\begin{tabular}{lcc}
\hline \multicolumn{1}{c}{ Country } & RETURN & XDY \\
\hline Germany & 0.00199 & 0.00423 \\
& $(0.07802)$ & $(0.03270)$ \\
France & 0.00346 & 0.00440 \\
& $(0.07447)$ & $(0.03190)$ \\
The Netherlands & 0.00485 & 0.00542 \\
& $(0.06643)$ & $(0.03316)$ \\
The United Kingdom & 0.00144 & 0.00436 \\
& $(0.06465)$ & $(0.03144)$ \\
Switzerland & 0.00520 & 0.00438 \\
& $(0.06720)$ & $(0.03534)$ \\
Europe & & -0.00117 \\
\end{tabular}

Notes. The sample consists of 225 monthly observations from March 1984 to November 2002. The table reports summary statistics (means and standard deviations in parenthesis) of monthly, US dollar-denominated excess stock returns. RETURN is the stock return for each country (Germany, France, the Netherlands, the United Kingdom, and Switzerland) are in excess of the riskless rate in the country and the European index return is in excess of the one-month Eurodollar rate. All variables are converted into US dollar terms. XDY is lagged dividend yield, in US dollar terms, in excess of 1-month Eurodollar rate. All series are stationary according to the ADF test.

\section{EMPIRICAL RESULTS}

We employ Beraert et al (2002) Sup-W test to determine the point estimates of the structural breaks and their confidence intervals. To identify specific dates of structural changes related to the integration of individual countries, we estimate individual VARs for each country, and compute the corresponding Sup-W test statistics for a series of univariate and multivariate tests.

For multivariate tests, we group different series in different systems to provide us information separately on the stock market (systems of series that include stock returns), the fixed income markets (systems of series containing interest rates), and the economic conditions (systems of series containing inflation). We also analyze different systems together to provide us a mix of information on the stock and fixed income markets and analyze it jointly with the SupW test. .

${ }_{4}^{3}$ http://wps.aw.com/aw solnik intlinv 5/0,7654,716896-,00.html

${ }^{4}$ http://www.federalreserve.gov

(C) 2011 The Clute Institute 
The univariate tests are designed to detect the timing of breaks in intercept and in the autoregressive coefficient for the market return, short rate, bond yield, inflation, and exchange rate for all countries. The multivariate tests include three bivariate tests and one four -variate test. The bivariate tests detect breaks in all coefficients of the bivariate vector autoregressions which have the following variables: (i) stock market return in excess of riskless rate and dividend yield in excess of riskless rate, (ii) inflation and exchange rate, and (iii) riskless rate and bond yield. The four 4-variate tests detect breaks in all coefficients of the 4-variate vector autoregressions, which include the stock returns and dividend yield for a country and the European stock market. The number of autoregressive lags determined by the Akaike information criterion is one for all cases. The test dimensions for the univariate, bivariate, and 4-variate cases are $q=1(1 \cdot 1+1)=2, \quad q=2(2 \cdot 1+1)=6, q=4(4 \cdot 1+1)=20$ respectively.

To illustrate the dynamics of the SupW statistics for the country stock markets, we present the graphs of Sup-W statistics for 4-variate system in Figure 1. The test results shows that a significant break occurred in all European countries in May-June 1986. In addition, the EMU countries had significant peaks of Wald statistics in the late 1990s and early 2000s: France has a significant peak in the test statistic at the 1\% level in April 2000, Germany has a significant peak in September 2000 at the 1\% level, and the Netherlands has the maximum Wald statistics in March 2001. This evidence indicates the possibility of a structural break in only the Euro-area countries in the 2000 -2001 period.

We next examine whether the timeline for peaks of the multivariate Wald statistics are related the economic and political events related to European integration ${ }^{5}$. The comparison shows that the 1986 structural break coincided with the following major events in 1985-86: the Second Intergovernmental Conference and the agreement on the Single European Act occurred in 1985, and in 1986 Spain and Portugal acceded to the EC. The second break in only the EMU-countries in 2000-01 coincides with the lauch of the single currency Euro on January 1999 by 11 member states, and the signing of the Treaty of Nice by the 15 member states in February 2001. These dates (only for the EMU countries) also coincide with the peaks of the Wald test statistic for the series that indicate changes in the capital markets and economic variables. In addition, the peaks appear to be occur in all countries at approximately the same time.

The maximum Wald statistics for the stock market variables are concentrated around the middle of 1986 (except for the Netherlands, which has the maximum test statistics in March 2001 in the four-variate case), with secondary peaks in the early 2000s. In addition, several economic variables including interest rates, exchange rates, and inflation rates also appear to have breaks in the mid-1990s. These changes could reflect the European currency crisis of September 1992 that lead to the breakdown of the Exchange Rate Mechanism in 1993. This findings is consistent with a high degree of volatility in financial integration in the 1990s in Fratzscher (2002), especially during the ERM crisis.

Our estimated event dates seem to be lagging the official dates when the key documents were signed; a similar effect was noted by Bekaert et al (2002) with respect to market liberalization of emerging countries. We conduct several robustness checks to verify that the changes indeed occurred around the estimated dates, and to identify which economic series they occurred, we conduct series of equality tests. First, we test whether sample means and variances for the following estimated series in our sample countries are equal before and after June 1986: the estimated conditional variances of returns, the estimated conditional covariances with the currency index, the estimated conditional covariances with the European return, the estimated prices of risks, and the estimated risk premia. The test results (not tabulated for brevity) confirm that the changes took place in all variables. The SupW test also indicates a number of dates in early 2000s that show several highly significant peaks of the Wald statistic for the EMU countries, suggesting that more changes may have occurred for the EMU compared to the non-EMU countres around the year 2000. To verify whether there was a second series of structural changes at that time, we test for equality in means and variances for the same set of series around April 2000 for France, September 2000 for Germany, and April 2001 for the Netherlands.

\footnotetext{
${ }^{5}$ The results of the univariate tests are consistent with the results of the multivariate tests presented here. 
Figure 1. The SupW statistics

$\square$

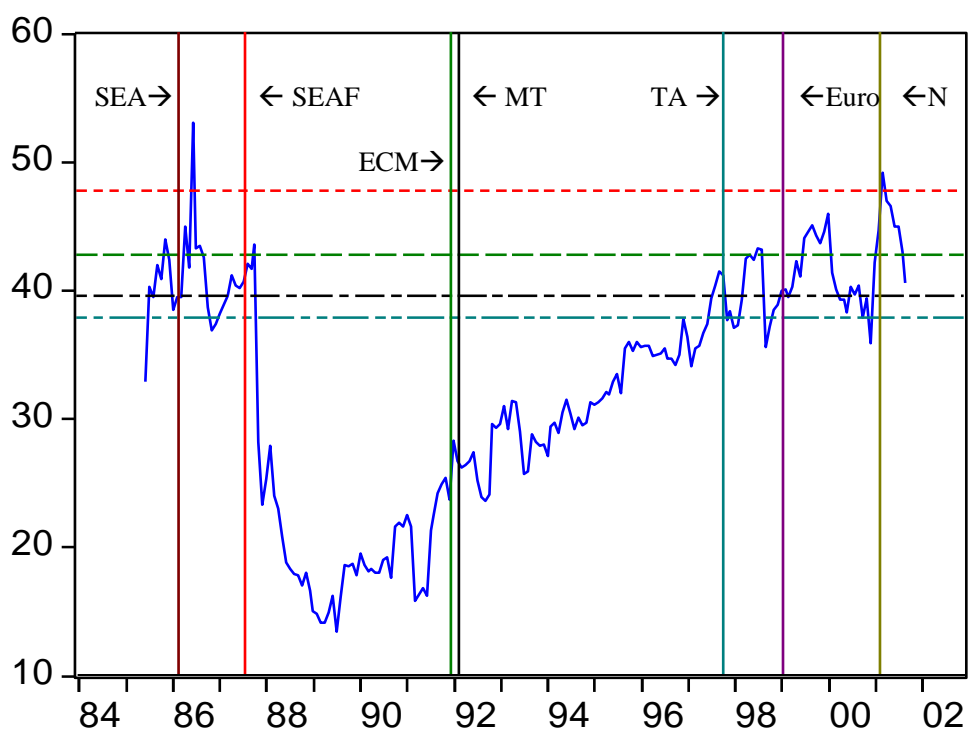

- $1 \%$ critical level $---10 \%$ critical level

$5 \%$ critical level _--- 15\% critical level

(a) France

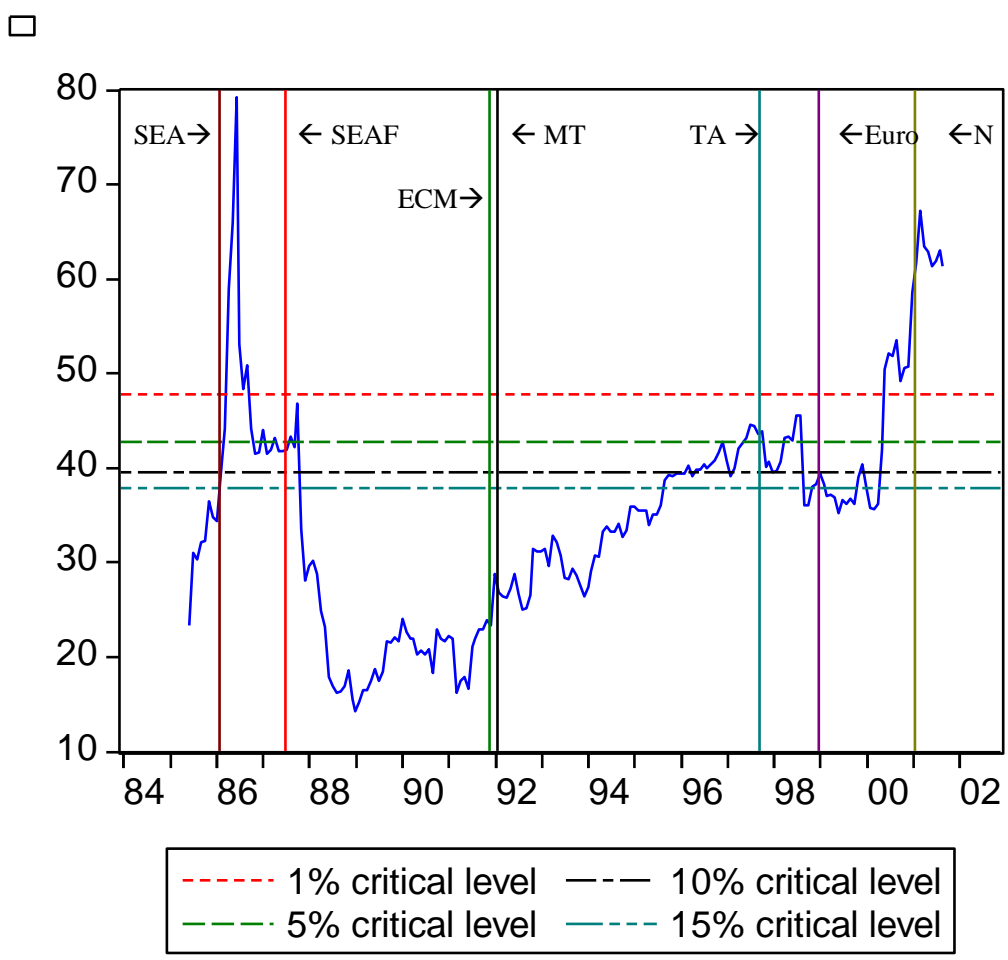

(b) Germany 
Figure 1 (continued). The SupW statistics

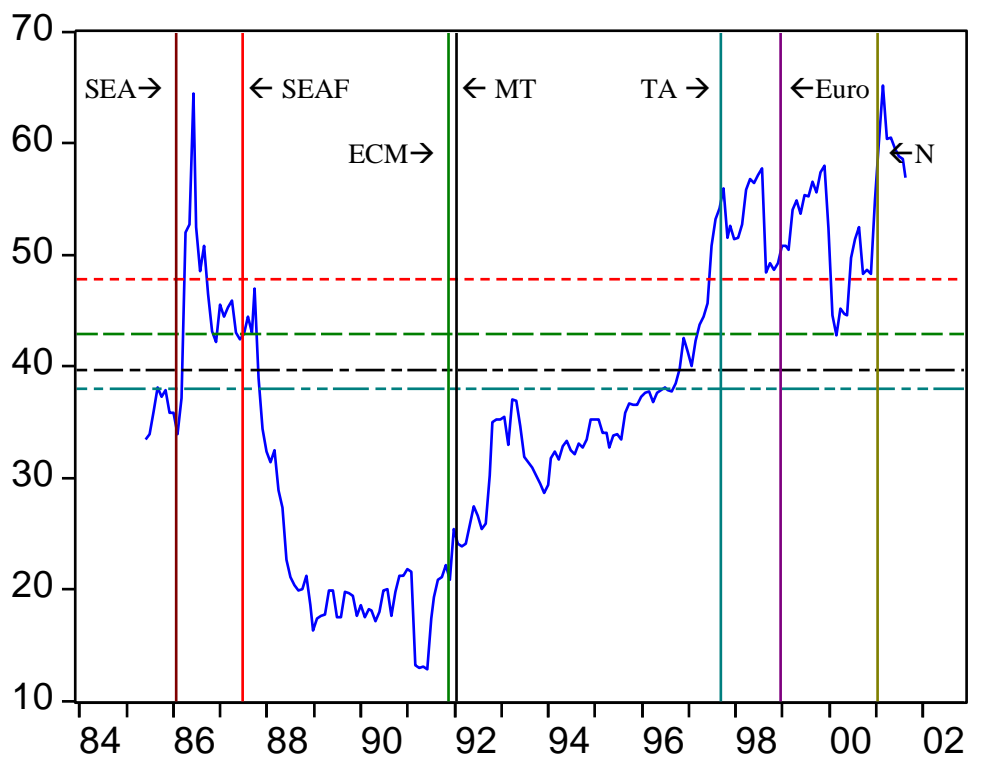

$-\ldots$ - $1 \%$ critical level $---10 \%$ critical level
$-\ldots-5 \%$ critical level $---15 \%$ critical level

(c) The Netherlands

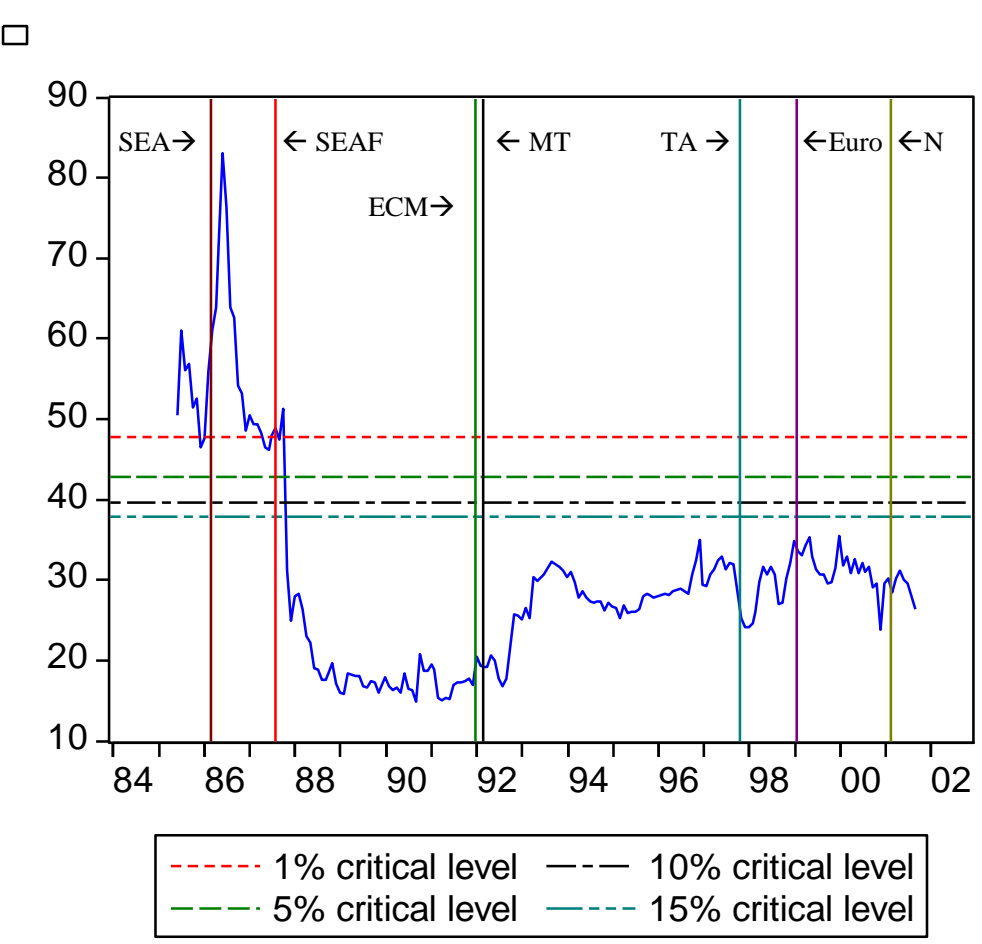

(d) The United Kingdom 
Figure 1 (continued). The SupW statistics

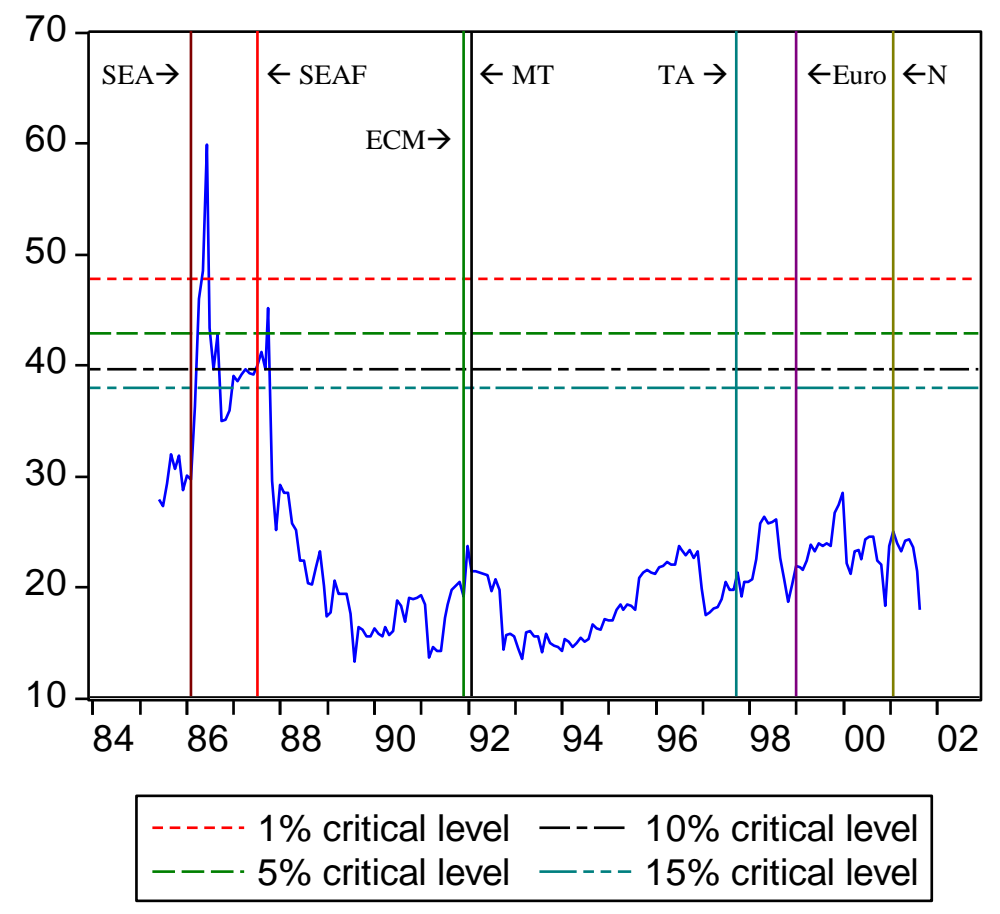

(e) Switzerland

Notes. SupW statistics for 4-variable VAR, order of autoregression $p=1$. The variables are: (i) stock return on each country (Germany, France, the Netherlands, the U.K., Switzerland), (ii) dividend yield for each country, (iii) stock return on Europe; and (iv) dividend yield for Europe. Number of lags in VAR is determined by Akaike information criterion, test dimension is $q=4(4 \cdot 1+1)=20$. SEA indicates when the Single European Act is signed in February 1986 in Luxembourg and The Hague. SEAF denotes The Single European Act entering into force on 1 July 1987. ECM indicates when The European Council meets in Maastricht in December 1991. MT indicates when the Treaty on European Union is signed in Maastricht on 7 February 1992. TA indicates when the Treaty of Amsterdam signed on 2 October 1997. Euro indicates when the Euro is launched in January 1999. N denotes signing the Treaty of Nice on 26 February 2001.

This is a short version of the timeline of the political events and the peaks of the SupW statistics. The full timeline of political events is available on request from the authors.

To test whether there were breaks in the non-EMU countries at that time, we also test hypotheses on the equality of means and variance for series related to the UK and Switzerland around September 2000. The test results (not reported here) provide some evidence for structural changes in the EMU countries, especially the Netherlands, which has the maximum Wald statistics in April 2001. To check robustness, we performed a regression-based procedure with heteroskedasticity and autocorrelation correction as in De Santis et al (2003, p. 456). This method produced results similar to those obtained by our equality of means tests.

To summarize, we are able to identify dates that displayed signs of structural changes in European asset pricing and these dates appear to around the time of major economic and political changes associated with the European liberalization process. Based on this evidence we conclude that the first break in the mid-1980s can be related to the expectation that Europe was going to have an economic union in the future whereas the second structural break in 1999 was associated with introduction of the Euro. 


\section{CONCLUSION}

This paper examines the effects of the European liberalization process on market integration by estimating the structural breaks in equity pricing in the European market index and individual European countries. We identify two dates of structural breaks in asset pricing for the European countries.

The first structural break affected all countries in our sample and took place around June 1986; it could be attributed to the signing of the Single European Act in 1986 that increased the expectations of a European economic and monetary union. The second structural break occurred only for the EMU-countries--in July 1999 for France and Germany, and in March 2001 for the Netherlands. This structural break can be attributed to the introduction of the Euro on January 1, 1999 in these countries. However, the integration process appears to be still evolving because it did not jump to full integration even after 1999 for the EMU countries.

We also conduct several robustness checks with different model specifications and estimation techniques. Our main findings remain essentially the same. Overall, our evidence supports that the liberalization process in Europe helped in integrating the capital markets of both EMU and non-EMU countries but the effect is more profound for the EMU countries.

\section{AUTHOR INFORMATION}

Sergiy Rakhmayil is an Associate Professor at Ted Rogers School of Management, Ryerson University. He holds his Ph.D. in Finance from the University of Manitoba. Professor Rakhmayil's teaching experience is in corporate finance, international finance, and personal financial planning. His research is in corporate finance, international finance, and financial equity markets.

\section{REFERENCES}

1. Bai, J., Lumsdaine, R. L., Stock, J., 1998. Testing for and dating common breaks in multivariate time series, Review of Economic Studies 65 (3), 395-432.

2. Bekaert, G., Harvey, C., 1995. Time-Varying World Market Integration, Journal of Finance 50, 403-444.

3. Bekaert, G., Harvey, C., Lumsdaine, R. L., 2002. Dating the integration of world equity markets, Journal of Financial Economics 65, 203-247.

4. Carrieri, F., 2001. The effects of liberalization on market and currency risk in the European Union, European Financial Management 7, 259-290.

5. De Santis, G., Gerard, B., 1998. How big is the premium for currency risk, Journal of Financial Economics 49, 375-412.

6. De Santis, G., Gerard, B., Hillion, P., 2003. The relevance of currency risk in the EMU, Journal of Economics and Business 55, 427-462.

7. Dumas, B., Solnik, B., 1995. The world price of foreign exchange risk, Journal of Finance 50 (2), 445-479.

8. Errunza, V., Losq, E., 1985. International asset pricing under mild segmentation, theory and test, Journal of Finance 40 (1), 105-124.

9. Fratzscher, M., 2002. Financial market integration in Europe, on the effects of EMU on stock markets, International Journal of Finance \& Economics 7 (3), 165-173.

10. Hardouvelis, G.A., Dimitrios, M., Priestley, R., 2006. EMU and European stock market integration, Journal of Business 79 (1), 365-392.

11. Solnik, B., McLeavey, D., 2002. International Investments, 5th ed. Addison-Wesley, New York. 